Brit. J. industr. Med., 1960, 17, 69.

\title{
RENAL LESIONS IN EXPERIMENTAL CADMIUM POISONING
}

\author{
BY \\ J. A. BONNELL, J. H. ROSS, and E. KING \\ From the Department for Research in Industrial Medicine, Medical Research Council, The London Hospital
}

(RECEIVED FOR PUBLICATION MARCH 12, 1959)

A series of controlled experiments was carried out on rats to study the effects on the kidneys of the repeated administration of small doses of cadmium for periods of up to 12 months. Renal lesions consisting essentially of tubular atrophy and interstitial fibrosis were produced, and the evidence that these lesions were due solely to cadmium is discussed. No similar lesions occurred in a series of control animals, litter mates of the experimental animals. The lesions were shown to be reproducible in two prolonged experiments on two strains of rats. The relationship between the lesions and the concentration of cadmium in the tissues of the rats is discussed and a comparison is made with tissues from human cases of chronic cadmium poisoning. It is of interest that the cadmium concentration of human tissues and rat experimental tissue is of the same order of magnitude. Animals in which the administration of cadmium was discontinued after five months of the experiment had developed as severe lesions seven months later as those animals which had received cadmium for 12 months. It has been shown previously that the first sign of chronic cadmium poisoning can occur in man for the first time many years after the last exposure, and that the disease once established in man is progressive despite the absence of further exposure.

Emphysema and proteinuria have been described in men exposed to cadmium oxide as either dust or freshly formed fume (Friberg, 1948; Bonnell, 1955). The significance of the proteinuria and its relationship to progressive renal damage has been discussed by Bonnell, Kazantzis, and King (1959).

Because the evidence that progressive renal damage occurred in men suffering from chronic cadmium poisoning was incomplete, experiments were carried out to study the effect of repeated small doses of cadmium on the kidneys of rats. These experiments are described here, together with a review of the literature involving animal experiments with cadmium.

\section{Review of the Literature}

The earliest work on the toxic effects of cadmium in animals was published by Marmé in 1867. He determined the lethal dose of 14 cadmium compounds on dogs, cats, rabbits, and pigeons. The cadmium was administered intravenously, subcutaneously, and orally. He found that the lethal dose for dogs was $30 \mathrm{mg}$. intravenously and 60-90 mg. subcutaneously. The lethal dose for rabbits was $300-600 \mathrm{mg}$. by mouth. Small doses of cadmium salts were found to produce chronic effects

6 but the actual doses were not mentioned. At necropsy these animals were found to have infarction of the lungs with subpleural haemorrhages, fatty degeneration of the liver and heart, and a diffuse inflammation of the kidneys. The excretion of cadmium was found to be slow and to occur mainly in the urine.

The effect of cadmium on the kidneys was studied by Severi in 1896. Ten milligrammes of cadmium as a $1 \%$ solution of cadmium chloride were injected subcutaneously in rabbits and dogs first daily and then on alternate days. The macroscopic and microscopic appearances of the kidneys were said to resemble closely the kidneys in mercuric chloride poisoning. There was an intense necrosis of the convoluted tubules, the cells were poorly defined, pale and with irregular granulations. There were tubular casts which appeared to be formed from the desquamating cells, and some calcified casts.

Alsberg and Schwartze (1919), using cats, dogs, rabbits, and rats as experimental animals, reported renal changes after parenteral administration but no histological details were given. No other pathological changes were noticed and no cumulative effects were noted with small doses.

Johns, Finks, and Alsberg (1923) showed that the 
growth of young rats was completely retarded by a diet containing 250 p.p.m. of cadmium. The initial growth rate was normal on diets containing 125 p.p.m. but all the male rats died within 56 days. Diets containing 62.5 p.p.m. produced no noticeable effects. Similar effects on growth were noted by Schwarz and Otto (1925) but they also reported a reduction in the haemoglobin content of the blood. Haemoglobin estimations in rats fed $1-11 \mathrm{mg} . / \mathrm{kg}$. of cadmium demonstrated a fall of 10 to $20 \%$ in the haemoglobin (Sahli scale).

Prodan (1932) devised a series of inhalation experiments on cats using cadmium fume, cadmium oxide, and cadmium sulphide. Two cats were exposed to a high concentration of cadmium fume for 30 minutes. One cat was killed five hours later and the other died 12 hours after exposure. Both had acute pneumonia. Three other cats were exposed for 24 hours to a lower concentration of cadmium fume (the settling curve showed an initial concentration of $16 \mathrm{mg} . / \mathrm{m}^{3}$ which fell to $4 \mathrm{mg} . / \mathrm{m}^{3}$ after 24 hours). All three cats developed acute pulmonary lesions. The first cat was killed immediately after exposure; the other two cats were killed five and nine days later. The lungs showed areas of acute inflammation, collapse, and acute emphysema. There were haemorrhages in the bronchioles and acute inflammatory changes in the liver and kidneys. Prodan estimated that the cats retained only 3 to $6 \mathrm{mg}$. of cadmium. In another experiment two cats were exposed to cadmium oxide dust at a concentration of $400 \mathrm{mg} . / \mathrm{m}^{3}$. The necropsy findings were similar to those in the animals exposed to cadmium fume. Cats exposed to cadmium sulphide showed changes in the lungs similar to those seen in animals exposed to cadmium fume and cadmium oxide dust.

Wilson, DeEds, and Cox (1941) studied the effect of adding cadmium to the diet of rats. Male albino rats were fed on diets containing $0,0.0031,0.0062$, $0.0125,0.025$, and $0.05 \%$ cadmium as cadmium chloride. Three effects were noticeable: (a) The effect on the growth of the animals; $(b)$ the production of anaemia; and (c) the effects on the teeth. The growth of the animals was retarded in direct relation to the concentration of cadmium in the diet. The rats taking $0.0125 \%$ cadmium in the diet were markedly affected after 84 days. When their diet was replaced with a normal diet, they rapidly attained a normal rate of growth with no apparent ill effects. Feeding on a diet containing as little as $0.0031 \%$ cadmium produced an anaemia which was sufficiently severe to alter the normally pink eyes of the albino rats. When the diet contained $0.0062 \%$ cadmium the haemoglobin dropped from a normal $16.5 \%$ to 3 to $4 \%$ in three months. The most sensitive criterion of chronic absorption of cadmium discovered in this work was the effect on the teeth. The normally yellow incisor teeth were bleached by cadmium, the effect being almost identical with that produced by fluorine poisoning. Statistically significant increases in weight were found for the heart, adrenals, and kidneys of these animals at necropsy. The mean weight of the hearts of rats on a diet containing $0.0125 \%$ cadmium was almost double that of the control animals. Microscopic examination of the heart showed hypertrophy of the cardiac muscle, which was claimed to be due to the anaemia and not to renal damage. Histological examination of the other organs showed a subacute pancreatitis, particularly in the rats absorbing $0.025 \%$ cadmium. There were focal areas of centrilobular necrosis with lymphocytic infiltration in the liver. There was swelling and granulation of the epithelium of the convoluted tubules of the kidneys with formation of both hyaline and granular casts. All these effects were more marked in the rats taking a diet containing 0.025 and $0.05 \%$ cadmium.

Princi and Geever (1950) described experiments in which dogs were exposed to cadmium sulphide and cadmium oxide dusts in specially constructed tanks. The dogs were exposed to cadmium oxide dust for six hours daily for five days each week at a mean concentration of $4 \mathrm{mg} . / \mathrm{m}^{3}$. Ninety-eight per cent. of the dust particles were less than $3 \mu$ in diameter and no particle greater than $5 \mu$ was seen. The dogs were exposed for periods which averaged 1,102 hours.

Complete necropsies on all $\mathbf{3 0}$ dogs showed no significant abnormalities. The lungs, liver, and kidneys were carefully examined, but even though appreciable quantities of cadmium were found in the organs, there were no structural changes. Blood cadmium levels varied between $0.3 \mu \mathrm{g} . / \mathrm{g}$. blood after one week and $2 \cdot 2 \mu \mathrm{g} . / \mathrm{g}$. after 12 months' exposure. The cadmium excreted in the urine was c. $6 \mu \mathrm{g}$./litre after one week and c. $387 \mu \mathrm{g}$./litre after 12 months' exposure. The blood and urine cadmium levels after exposure to cadmium sulphide were much lower. The cadmium concentration in the liver and kidney was 20.6 to $133 \mu \mathrm{g}$./g. of kidney and 12.4 to $4.70 \mu \mathrm{g}$./g. of liver. Princi suggested as a result of these experiments that the maximum allowable concentration of cadmium in the atmosphere of workshops should be increased.

Friberg (1950a and b) described experiments in which rabbits were exposed to cadmium dust in two groups of 13 and 12 for seven and nine months respectively. The first group were exposed for seven months to dust of cadmium and iron (containing $20 \%$ of iron) at a concentration of $10 \mathrm{mg} . / \mathrm{m}^{3}$. 
They were exposed for three hours daily, six days a week. The second group were exposed to the same dust in the same way for nine months. The average concentration of the dust in the atmosphere was $7 \mathrm{mg} . / \mathrm{m}^{3}$. Ninety-five per cent. of the dust particles were less than $5 \mu$ in diameter and $55 \%$ were less than $1 \mu$.

The urine was tested periodically with $25 \%$ trichloracetic acid and $25 \%$ nitric acid. From the fourth month onward proteinuria was found, increasing in incidence with time. Twenty-two rabbits survived the experiment and of these nine had a constant proteinuria from the fourth month, six had proteinuria during half of the time tested, five had proteinuria on isolated occasions, and no proteinuria was demonstrated at any time in two. At necropsy, 16 showed a chronic inflammation of the nasal mucous membranes, 20 had chronic tracheitis, and all were found to have chronic bronchitis and emphysema. There was fatty infiltration of the liver and inflammatory foci were found in the kidneys of the majority. The kidneys contained $300-700 \mu \mathrm{g}$./g. of cadmium, the liver $100-400 \mu \mathrm{g}$. $/ \mathrm{g}$., and the lungs $50-150 \mu \mathrm{g}$. $/ \mathrm{g}$.

In a second experiment, 15 rabbits were injected subcutaneously with $0.3 \%$ solution of cadmium sulphate in water $\left(1 \mathrm{ml}\right.$. contained $3 \mathrm{mg}$. $\mathrm{CdSO}_{4} \equiv$ $1.3 \mathrm{mg}$. Cd). Each rabbit was given $0.5 \mathrm{ml}$. $/ \mathrm{kg}$. of body weight once daily for six days each week. Six rabbits were killed after two months, five survived for six months and were killed, and four died during the course of the experiment. Proteinuria was demonstrated in all the animals after two months. The protein was shown to behave differently on physico-chemical examination from the protein produced in uranyl nephritis in rabbits. All the animals became progressively more anaemic.

At necropsy the livers were granular and of abnormally firm consistency. The spleens were enlarged, weighing five times as much as the spleens from control rabbits. Chronic inflammatory changes were present in the upper respiratory tract. The liver showed a pronounced periportal cirrhosis and there was a non-specific hyperplasia of the spleen. The kidneys showed chronic inflammatory changes with interstitial infiltration of lymphocytes as well as plasma cells. Hyaline casts were present in the tubules.

Dalhamn and Friberg (1957) in a later series of experiments described renal tubular necrosis in rabbits after 10 weeks' subcutaneous injection of cadmium sulphate as described above.

There are several conflicting reports of renal involvement in animals given cadmium either by mouth or parenterally. In none of the reports are detailed descriptions of renal histology given and for this reason the following experiments were carried out.

\begin{abstract}
Method
Male and female albino rats of the Wistar strain, "Glaxo" and "Chester-Beatty" breeds, aged 3 months and weighing about $200 \mathrm{~g}$., were used in the experiments. Cadmium was given by intraperitoneal injections as a solution of cadmium chloride in distilled water $(1 \mathrm{ml}$. $\equiv 1 \mathrm{mg}$. Cd). At this dilution the solution was neutral. In all these experiments, the rats were killed at intervals by chloroform anaesthesia, necropsies were performed, and the livers and kidneys were examined histologically. Tissues were fixed in formol saline. Sections of $5 \mu$ thickness were cut and stained with haematoxylin and eosin and a connective tissue stain. In some cases frozen sections were cut and stained with Sudan III to show fat. In six cases at the end of the experiment cultures were made on blood agar and McConkey media from kidneys sectioned with sterile precautions. Urine was obtained from rats in experiments 2 and 3 by holding the animal over a petri dish and stimulating micturition by ether inhalation. The urine was collected in a pipette and the uncentrifuged deposit was examined microscopically.
\end{abstract}

\section{Results}

Experiment 1.-Six pairs of female rats were given single intraperitoneal injections of cadmium at a dose of $2 \cdot 5,3,4,5,6$, and $7 \mathrm{mg}$. Cd/kg. The rats given 6 and $7 \mathrm{mg}$./Cd. $/ \mathrm{kg}$. died within 12 hours, of those given 4 and $5 \mathrm{mg}$. Cd./kg., three died within 12 hours and the other was killed four days later. The four remaining rats which received 2.5 and $3 \mathrm{mg}$. Cd/kg. were unaffected; two were killed 24 hours later, one after four days and one after three months. Necropsies were performed on all five animals killed and the liver and kidneys were examined histologically. No macroscopic or microscopic abnormalities were found in the liver and kidneys of these five rats. Frozen sections were not obtained. These doses of cadmium were not well tolerated and the animals appeared to suffer from an acute irritative peritoneal lesion. Animals killed or dead within 24 hours of the injection had an acute haemorrhagic peritonitis with a blood-stained effusion.

Experiment 2.-A pilot experiment to study the effect of repeated injections of cadmium was begun in January, 1955. Ten female and eight male rats, aged 12 weeks and weighing from 150 to $200 \mathrm{~g}$. were given intraperitoneal injections of cadmium thrice weekly at a dose of $1 \mathrm{mg}$. Cd/kg. Two male rats were used as control animals and were given intraperitoneal injections of physiological saline. Microscopical examination of the urine was carried out on a number of rats each week. Single rats were killed each week from the sixth to the ninth, 


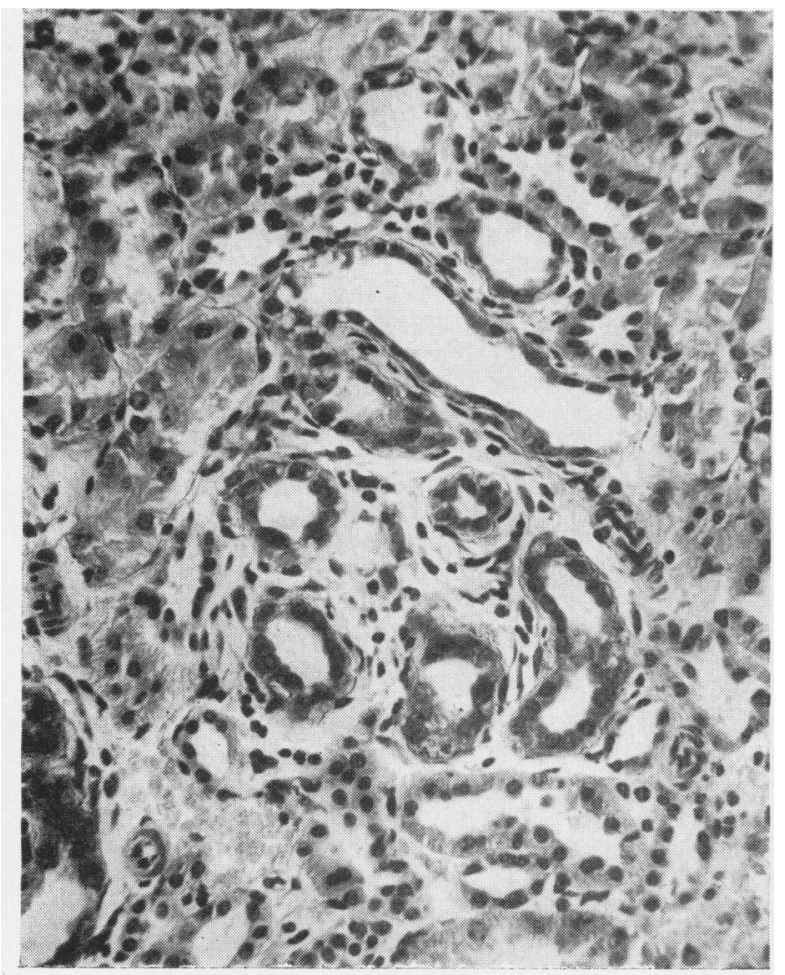

Fig. 1.-Rat 19, female, killed at eight weeks. Haematoxylin and eosin, $\times 300$. Small area with dilated tubule, convoluted tubules with flattened basophil cells and surrounding interstitial reaction.

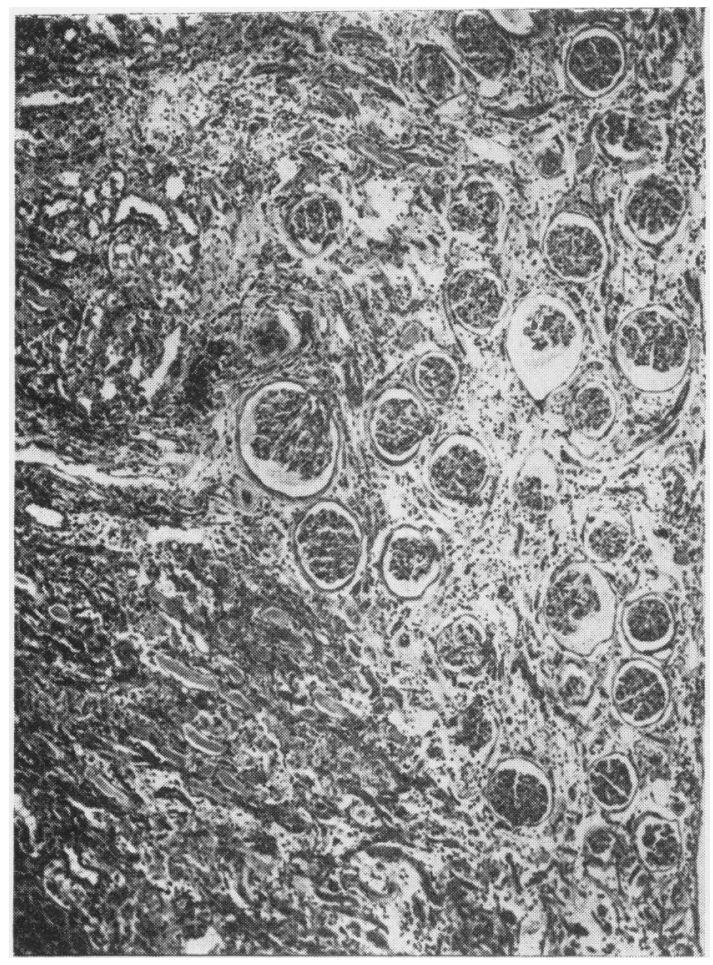

FIG. 3.-Rat 21, female, killed at 45 weeks. Haematoxylin and eosin, $x$ 59. Cortex with marked tubular atrophy and crowding together of glomeruli, some of which have shrunken tufts and dilated capsular spaces.

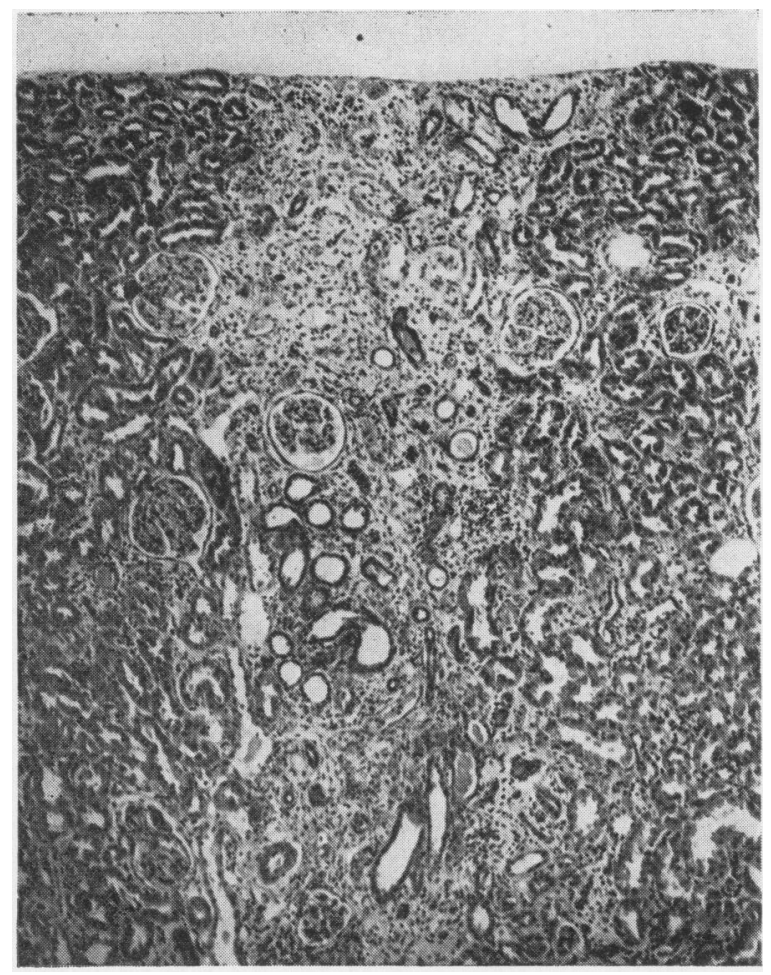

Fig. 2.-Rat 5, male, $k$ i led at 28 weeks. Haematoxylin and eosin, $\times$ 75. Subcapsular area with tubular atrophy and dilatation and increased interstitial tissue.

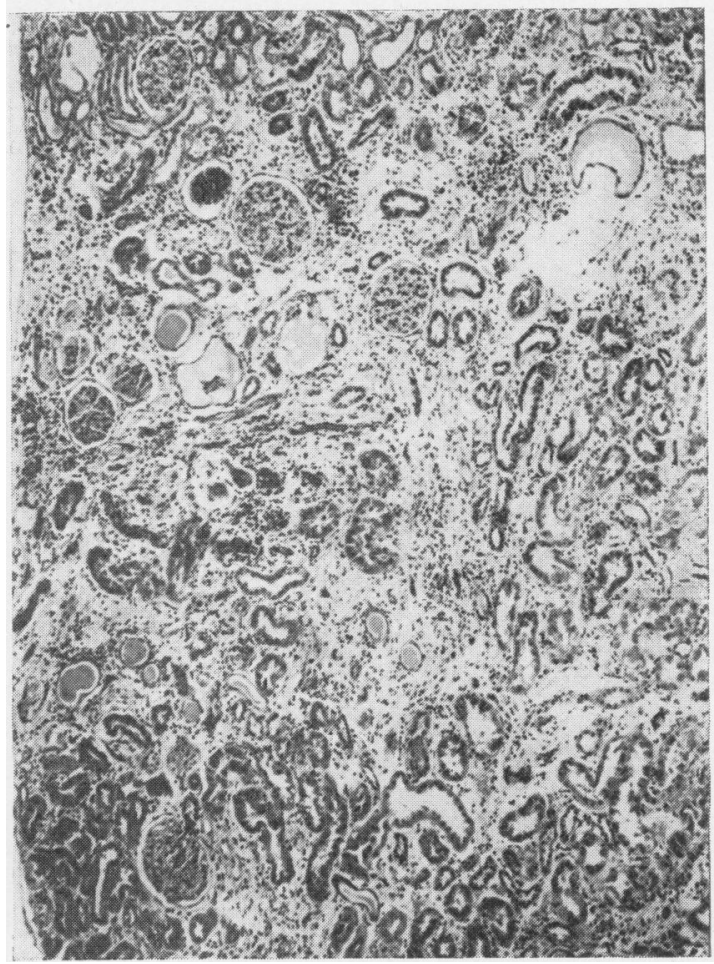

Fig. 4.-Rat 20, female, killed at 45 weeks. Haematoxylin and eosin, $\times 68$. Cortex with tubular atrophy and occasional dilatation and increase in interstitial tissue.

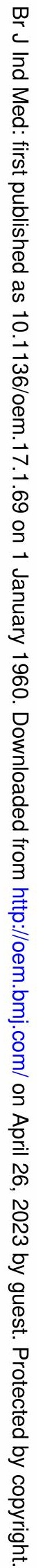


14th-18th, and 23rd-29th weeks inclusive and the remainder at the 32nd and 45th weeks.

Urine Examination.-Excess red blood cells and granular and cellular casts were regularly found in the urine of all rats receiving intraperitoneal cadmium after one month.

Macroscopic Findings.-There was evidence of peritoneal reaction to the cadmium injections in all these rats. Free fluid was frequently found in the peritoneal cavity and the peritoneum covering most organs and lining the abdominal wall was irregularly thickened by fibrosis. The liver was distorted by fibrous bands replacing peritoneum in rats killed after three months (but microscopic examination showed no intrahepatic lesions). The heart and lungs appeared normal.

The kidneys of rats killed up to 24 weeks appeared normal on section. After 24 weeks blurring of the cortical pattern and corticomedullary junction was occasionally noted. The kidneys of one female rat killed at 32 weeks and of the two female rats killed at $\mathbf{4 5}$ weeks were contracted with finely granular surfaces, contracted blurred cortices, and absent or ill-defined corticomedullary demarcations.

Microscopic Findings.-The kidneys of rats killed at six, seven, eight, and nine weeks showed: (a) no abnormality (two rats), or (b) vacuolation with a slightly ragged appearance of the cells of the convoluted tubules (one rat), or (c) a few small areas in the cortex, usually subcapsular, containing dilated tubules with eosinophil cast material, slightly increased interstitial tissue and very slight interstitial lymphocytic infiltration. Flattened basophil tubular cells were considered to indicate regenerative activity (two rats) (Fig. 1).

The kidneys of rats killed from 14 to 45 weeks showed lesions as in (c) above, their severity increasing with the duration of the injections. The normal architecture of the kidneys was altered by irregular areas of tubular destruction. This consisted of tubular atrophy with tubular remnants lying within increased interstitial tissue containing a few chronic inflammatory cells (Fig. 2). Occasional tubules were dilated with flattened lining cells and contained eosinophil material. In the least involved specimens the affected areas were mostly subcapsular and approximately wedge-shaped with slight "dimpling" of the capsular surface; deeper in the cortex the areas were irregular. The glomeruli were normal, apart from some dilated capsular spaces and shrunken tufts in the most advanced specimens. Medullary tubules contained eosinophil casts and were occasionally surrounded with a few chronic inflammatory cells.
The lesions were most marked in the kidneys of rats killed after 32 weeks, in which the tubular destruction had led to cortical contraction and fibrosis with crowding together of the glomeruli (Figs. 3 and 4). Fat stains showed that the surviving convoluted tubules in some specimens contained many fat-filled vacuoles. Regenerative activity in some tubules was frequently noted.

The kidneys of two male rats given intraperitoneal saline for 23 and 28 weeks showed no abnormalities.

Experiment 3.-The pilot experiment demonstrated that renal lesions could be produced by cadmium injected intraperitoneally. In order to study this lesion in greater detail and to confirm that the results were reproducible a further experiment was started in January, 1956. In this experiment 35 male and 30 female rats were given cadmium by intraperitoneal injections at a dose of $0.75 \mathrm{mg}$. Cd/kg. thrice weekly. Twenty male and 20 female rats, litter mates of the experimental animals, were used as controls; these animals were given intraperitoneal injections of distilled water thrice weekly. Four experimental rats, two female and two male, together with two control rats, one female and one male, were killed each month. Necropsies were carried out on each animal, the liver and kidneys were examined histologically, and the cadmium content of all the tissues was determined by polarographic analysis. Since rats have a physiological proteinuria, no estimations of urinary proteins were carried out.

This experiment had to be modified slightly because after five months the male rats and after six months the female rats showed signs of severe debility and the injections were discontinued until the end of the seventh month. At this time nine male and nine female rats were given further injections of cadmium chloride, but at a reduced dose rate of $0.25 \mathrm{mg} . \mathrm{Cd} / \mathrm{kg}$. thrice weekly. The remaining five male and five female rats were not given any further doses of cadmium. The control rats continued to receive intraperitoneal injections of distilled water throughout the experiment.

At the end of the experiment the exposed animals consisted of a group of males which had been dosed for five months and left for a further seven and a group of female rats dosed for six months and left for six months, together with a group of males and a group of female rats which were given $0.75 \mathrm{mg}$. $\mathrm{Cd} / \mathrm{kg}$. for five and six months and then $0.25 \mathrm{mg}$. $\mathrm{Cd} / \mathrm{kg}$. from the seventh to the twelfth months.

Sections from the kidneys of $\mathbf{3 5}$ control rats and 59 rats injected with cadmium were available for histological study; five control rats and six cadmium-injected rats died and their kidneys were 


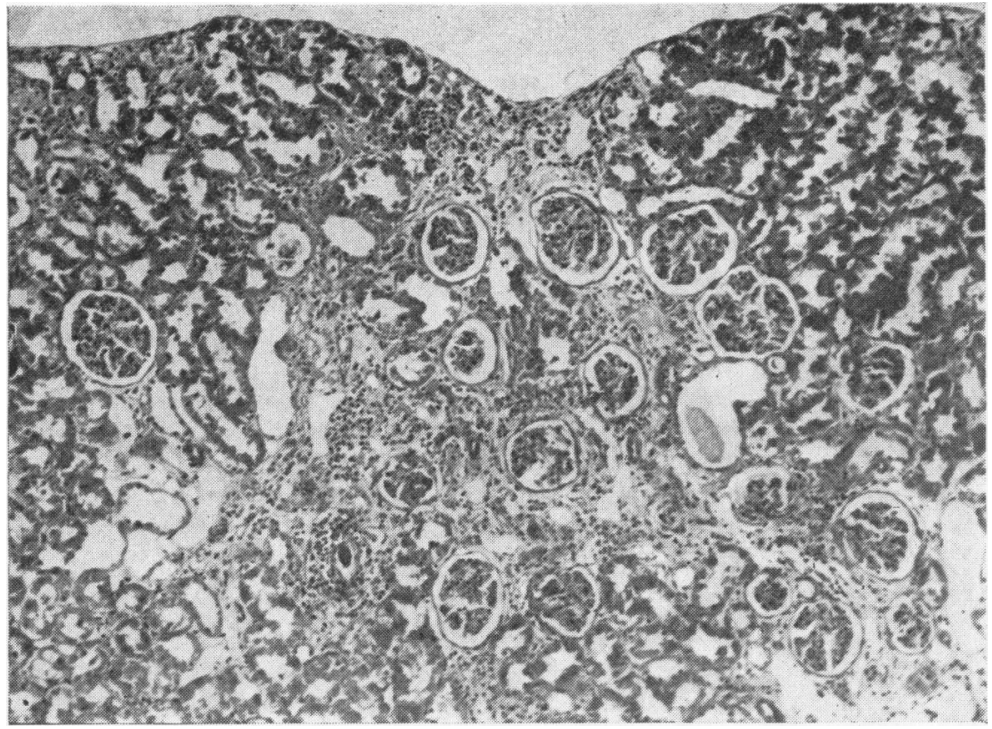

Fig. 5.-Rat 27, female, killed at twelve months. Haematoxylin and eosin, $\times 80$. Cortical area of contraction with tubular atrophy and dilatation and crowding together of glomeruli.

too damaged for examination. In some of these cases the tissues were suitable for chemical analysis. On other occasions mishaps during the preparation of tissues made chemical analysis impossible.

The microscopic renal lesions observed were identical in nature to those found in experiment 2 but less severe; kidneys from rats killed at 45 weeks in experiment 2 showed more extensive lesions than those from rats killed at 52 weeks in this experiment (Fig. 5).

The lesions have been graded as follows:-

0-No abnormality other than occasional vacuolation within cells of convoluted tubules.

1 -Very small areas with tubular atrophy, slightly dilated tubules containing casts and slight chronic inflammatory cell infiltration.

2-Many areas in cortex of tubular atrophy with associated features as in 1 , and with increased interstitial tissue.

3-Cortex almost uniformly involved by lesions as in 2 , with or without cortical contraction and crowding together of glomeruli.

Table 1 shows the numbers of rats at different periods with lesions of grades 0 to 3 . Those rats which had obvious pyelonephritis with marked polymorphonuclear leucocyte and chronic inflammatory cell infiltration are indicated under a separate heading as is one rat which had an abscess in one kidney. The lesions were bilateral and of approximately equal severity in each kidney. No lesions were found before four months; they became more marked with longer durations (Fig. 6). Rats which were killed at nine and 12 months but had not been injected after six months had lesions of similar

TABLE 1

GRADING OF MICROSCOPIC LESIONS IN CADMIUM-INJECTED AND CONTROL RATS

\begin{tabular}{|c|c|c|c|c|c|c|c|c|c|c|c|c|}
\hline \multirow{2}{*}{ Month } & \multicolumn{2}{|c|}{0} & \multicolumn{2}{|c|}{1} & \multicolumn{2}{|c|}{2} & \multicolumn{2}{|c|}{3} & \multicolumn{2}{|c|}{ Pyelonephritis } & \multicolumn{2}{|c|}{ Abscess Formation } \\
\hline & Control & Cd & Control & Cd & Control & $\mathbf{C d}$ & Control & Cd & Control & Cd & Control & Cd \\
\hline $\begin{array}{l}1 \\
2 \\
3 \\
3 \frac{1}{2} \\
4 \\
5 \\
5 \frac{1}{2} \\
6 \\
6 \frac{1}{2} \\
7 \\
7 \frac{1}{2} \\
8 \frac{1}{2} \\
9 \\
12\end{array}$ & $\begin{array}{r}1 \\
2 \\
2 \\
1 \\
1 \\
2 \\
2 \\
2 \\
1 \\
15\end{array}$ & $\begin{array}{l}6 \\
3 \\
4 \\
1 \\
2 \\
2\end{array}$ & $\begin{array}{l}2 \\
1\end{array}$ & $\begin{array}{c}2 \\
3 \\
\\
2 \\
1 \\
2(2) \dagger \\
2\end{array}$ & & $\begin{array}{c} \\
3 \\
1 \\
2 \\
1 \\
1 \\
2(1) \\
6(2)\end{array}$ & & $\begin{array}{r}1 \\
1 \\
1 \\
6(2)\end{array}$ & $\begin{array}{l}1 \\
1\end{array}$ & 1 & & 1 \\
\hline
\end{tabular}

+ Figures in brackets indicate numbers of rats, included in the adjoining total, which were not injected after six months. 
Fig. 6.-Rat 10, female, killed at four months. Haematoxylin and eison, $\times$ 150. Early subcapsular lesion.

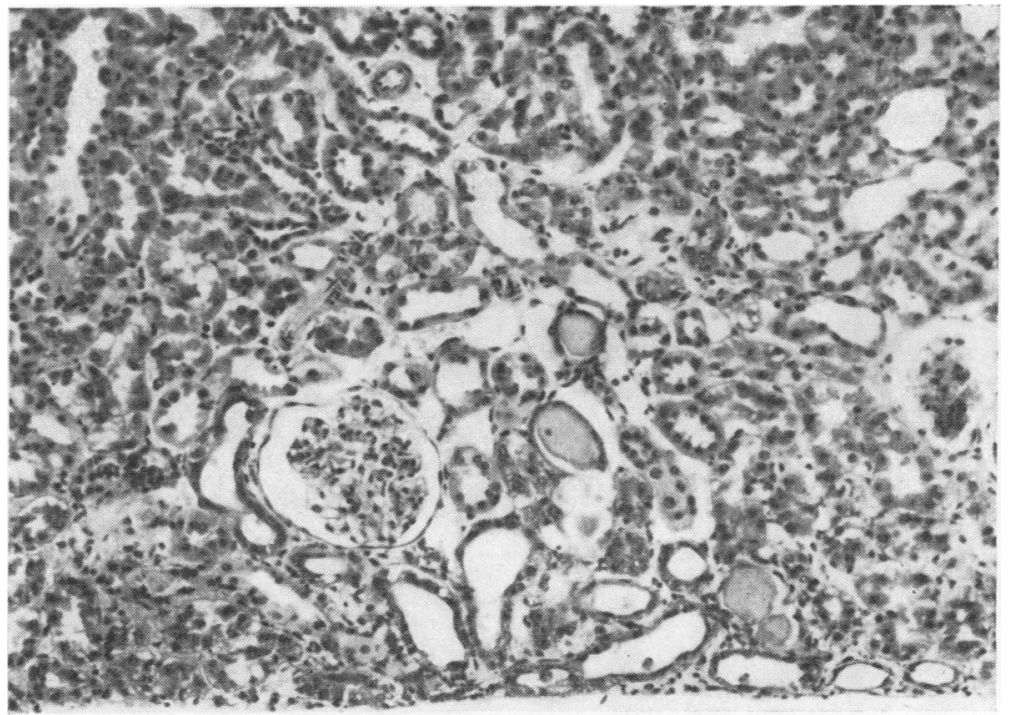

intensity to those injected up to nine and 12 months.

The kidneys of three control rats had very small areas of tubular atrophy with surrounding small round cell infiltrations. These lesions were similar to those graded 1 in the cadmium-injected rats and have been graded as such, although, in one instance. the inflammatory cell infiltration was more marked.

Pyelonephritis was obviously present in some areas of the kidneys of one cadmium-injected rat

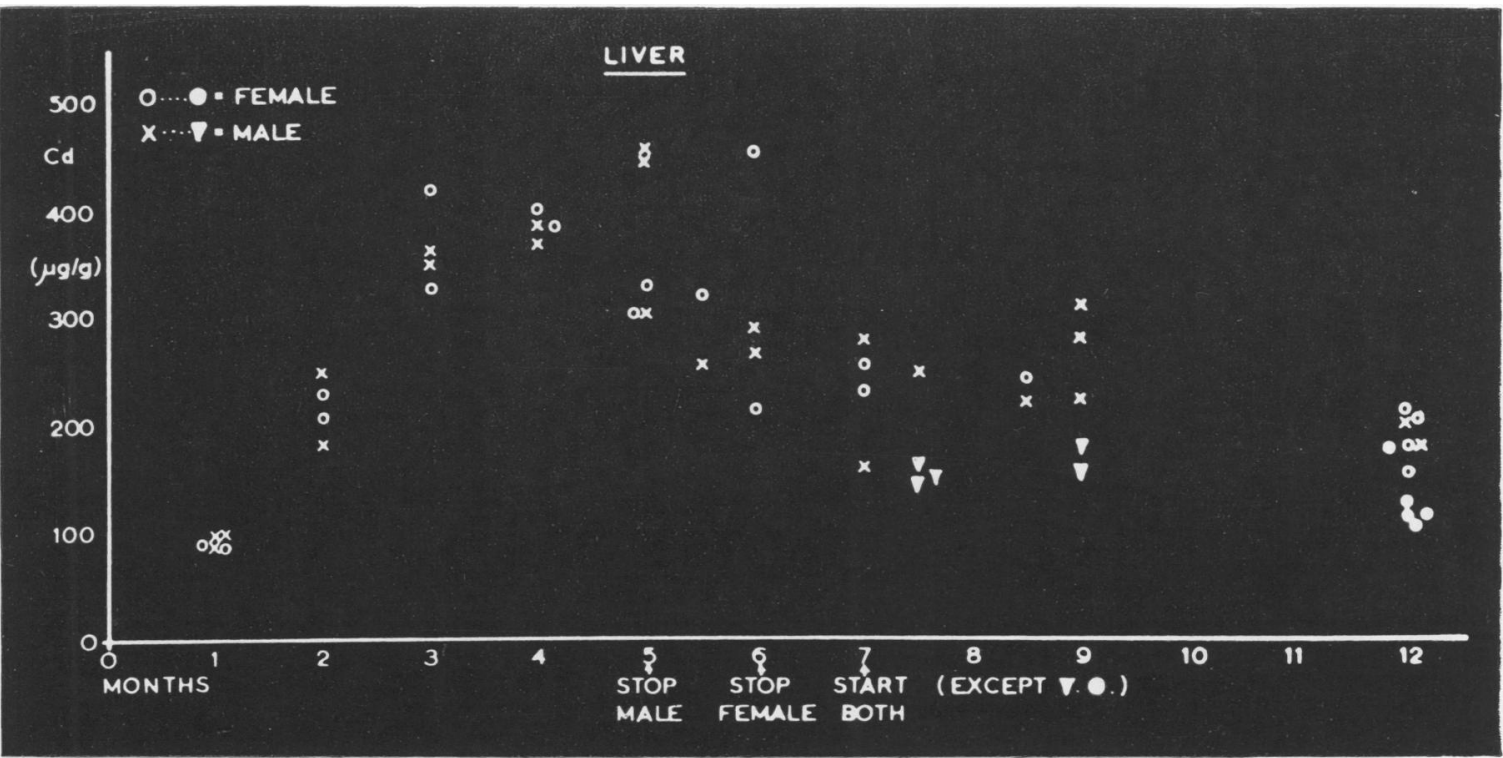

Fig. 7.-Tissue concentration of cadmium in the liver.

killed at six months, which was graded 2 as elsewhere there were areas of tubular atrophy without marked interstitial inflammatory infiltration. In addition one cadmium-injected rat killed at 12 months had a few polymorphonuclear leucocyte tubular casts in addition to widespread tubular atrophy and distortion.

Within four to five months the central incisor teeth of the cadmium-injected rats became bleached 


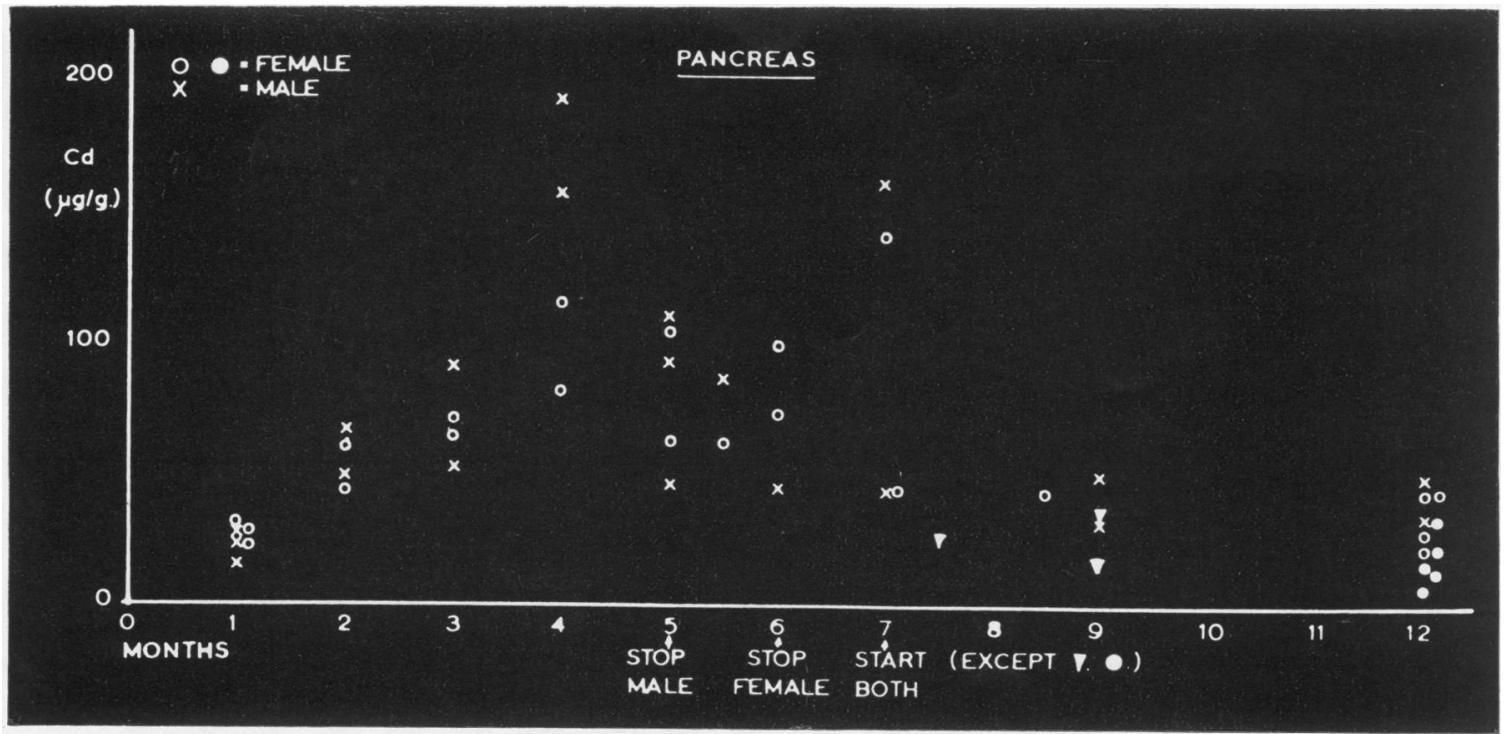

FIG. 8.-Tissue concentration of cadmium in the pancreas.

and appeared white compared with the normal orange-yellow colour of the teeth of the control rats. This bleaching of the teeth was permanent and confirms the findings of Wilson et al. (1941).

\section{Tissue Concentration of Cadmium}

The concentrations of cadmium in the liver, kidneys, spleen, and pancreas of the experimental animals are shown graphically in Figs. 7-10.
It can be seen from Fig. 7 that the liver concentrations of cadmium increased linearly up to the third month, when a plateau was reached. The concentration of cadmium then fell rapidly in the two months following cessation of the injections and then more gradually until the end of the experiment. The liver concentrations of those animals in which the injections were recommenced at the lower dosage did not attain their former high level.

The concentration of cadmium in the pancreas

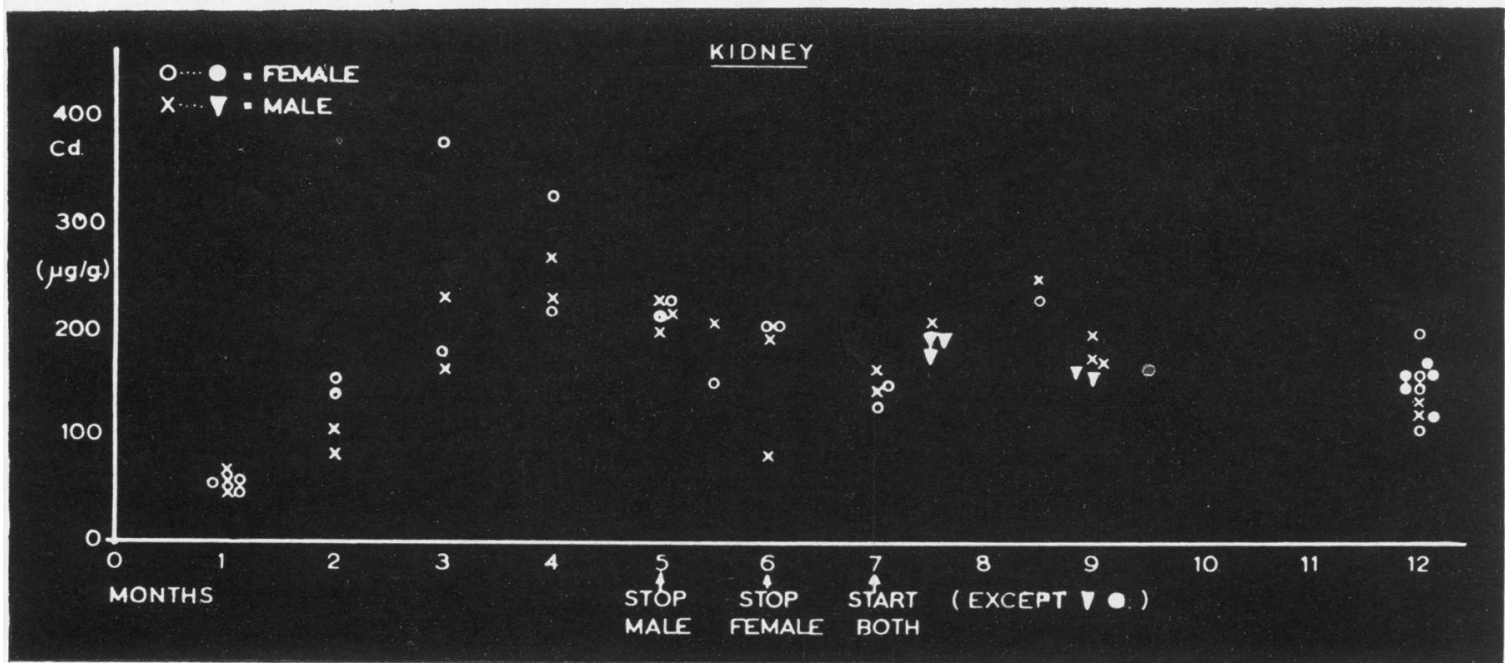

FIG. 9.-Tissue concentration of cadmium in the kidneys. 


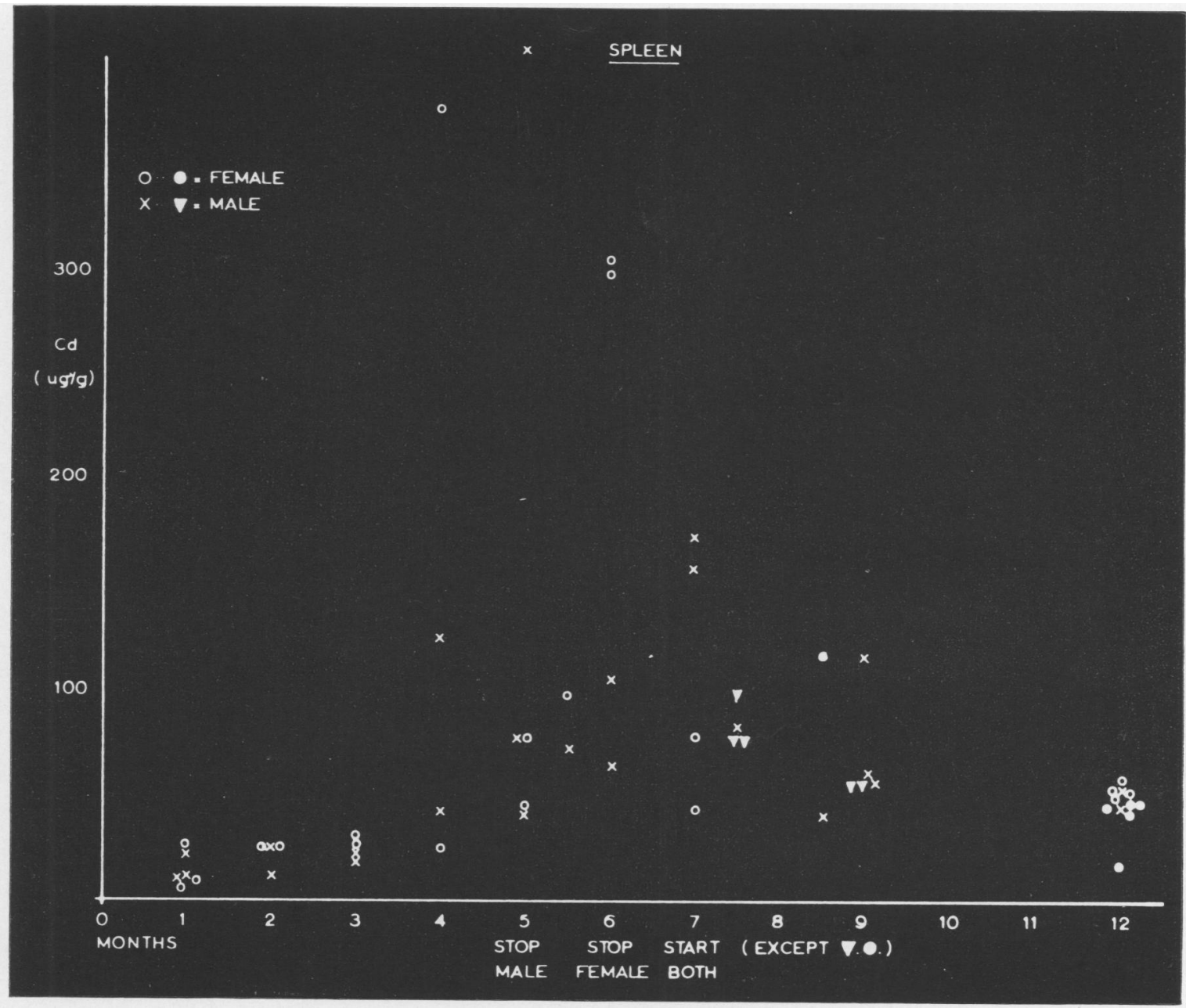

FIG. 10.-Tissue concentration of cadmium in the spleen.

closely paralleled that in the liver, but at a lower level (Fig. 8).

The cadmium concentration in the kidneys (Fig. 9) also increased linearly for the first three to four months after which a plateau was reached. It can be observed that there was little decrease in these levels after dosage had been stopped and that the further injections of small quantities of cadmium did not increase the levels above those of the animals which were not injected after six and seven months.

The spleen contained little cadmium until the fifth month when the concentration rose sharply to a very high level and then decreased rapidly on cessation of dosage (Fig. 10).

The blood cadmium levels were high during the fourth, fifth, and sixth months of the experiment, amounting to an average concentration of $10 \mu \mathrm{g}$. $\mathrm{Cd} / \mathrm{ml}$. blood. The cadmium was present in the red blood cells and not in the plasma, confirming the findings of Friberg (1952). The high splenic cadmium concentration occurred one to two months after the high blood levels were first observed, suggesting that they were connected with the destruction of circulating red blood cells. By the end of the experiment the blood cadmium concentrations were insignificant. Other tissues examined were voluntary muscle, heart muscle and involuntary muscle, lungs, skin, long bones, sternum and vertebrae (with and without marrow), teeth and jaw, brain, salivary glands, thyroid, adrenals, testes, and ovaries, but in none of these tissues were sig- 
nificant trends in concentrations of cadmium found. Since rat prostate contains relatively high concentrations of zinc, repeated examination of the prostate for cadmium was carried out in order to ascertain whether cadmium replaced zinc in vivo, but no significant increase was found.

Tissue analyses of the control animals showed an increasing amount of cadmium in the tissues, but of very much lower amounts. It was eventually discovered that the M.R.C. rat diet 41 contained 5-10 $\mu \mathrm{g}$. of cadmium per gram of food. This was later found to be due to the fish meal used to provide the protein in the diet. A sample of the latter supplied by the manufacturers of the diet was found to contain $160 \mu \mathrm{g}$. $\mathrm{Cd} / \mathrm{g}$. The small cadmium concentrations in the tissues of the control animals do not affect the results of the experiment since all the animals were fed on the same diet.

The growth curves of the experimental animals were of similar form to those of the control animals, but at a lower level. The female experimental animals had a final average weight of c. $220 \mathrm{~g}$. compared with c. $245 \mathrm{~g}$. for the controls, and the male experimental animals c. 240 g. compared with c. $370 \mathrm{~g}$. for their controls. The weights illustrate that, as in the general condition of the animals observed during the experiment, the male rats were more severely affected than the females, despite their dosage at $0.75 \mathrm{mg}$. $/ \mathrm{kg}$. for one month less than the females. No differences between the sexes were observed in tissue concentrations or histological findings at any stage of the experiment.

\section{Discussion}

The concentrations of cadmium in the livers and kidneys of the rats of experiment 3 were similar to those found in the post-mortem tissues of men who had been exposed to cadmium oxide fume, and the ratio of kidney concentration to that of the liver after dosage had been stopped followed a similar relationship but on a different time scale. The failure of other experimental workers, notably Princi and Geever (1950), to produce renal lesions in animals was probably due to their use of a lower dosage rate, which resulted in lower concentrations of cadmium in the liver and kidney than in the experiments now reported or in human postmortem specimens. Thus the apparently high dosage rate of $0.75 \mathrm{mg} . / \mathrm{kg}$. thrice weekly is in fact one which the rats could tolerate to give tissue concentrations similar to those in workmen who received a lower dosage rate over a longer period.

The renal lesions resemble those of chronic pyelonephritis which is known to produce atrophy and distortion of tubules, increase of interstitial tissue, chronic inflammatory cell infiltration, and secondary ischaemic changes in the glomeruli.

Progressive tubular atrophy due to chronic infection, ischaemia, or cellular degeneration would be expected to produce lesions closely resembling one another with variations depending on the size of the obliterated blood vessels or the particular part of the tubules affected. Lymphocytes and occasional plasma cells may be associated with lesions without an infective cause, but infection is of course frequently associated with renal lesions of which the origin is obstructive or degenerative.

Tubular dilatation, mainly medullary, with increased amounts of interstitial tissue and mild inflammatory changes have been described as ageing changes in rats (Saxton and Kimball, 1941) and may add to the difficulty in interpreting experimental renal lesions but were not observed in the control animals in the experiments described in this paper.

The tubular cells are more likely to be subjected to a high concentration of some toxic substances than cells elsewhere in the body. Tubular atrophy from this cause or from interference with the normal metabolic processes of the cells may well prove to be responsible for certain examples of renal damage which are at present considered to be due to chronic pyelonephritis. An example of the difficulty in determining the origin of such renal lesions has arisen during the study of the effects of chronic potassium depletion on men and animals (Fourman, McCance, and Parker, 1956; Milne, Muehrcke, and Heard, 1957; Relman and Schwartz, 1958); minor cellular lesions are definitely associated with potassium depletion of short duration but chronic pyelonephritis has not yet been excluded as a cause of the chronic irreversible changes which have been observed. It is not possible to prove conclusively that the lesions described in this paper are not due to pyelonephritis occurring in sick rats but the evidence suggesting that they are the result of tubular atrophy due to cadmium poisoning is discussed below:

(1) The lesions observed in the kidneys of these animals differ in certain respects from those of chronic pyelonephritis. Chronic inflammatory cells although present were never as prominent as in pyelonephritis. The lesions were usually subcapsular in early cases and predominantly cortical in the later ones; the radial streaks of chronic inflammation, usually found in pyelonephritis, were not seen. Inflammatory changes beneath the pelvic epithelium were not found except in rats which had definite evidence of pyelonephritis with gross inflammatory lesions elsewhere in the renal parenchyma. "Thyroid" tissue, frequently found in chronic pyelonephritis, was not observed. 
(2) If the lesions described had been produced by pyelonephritis acute focal inflammatory changes would have been expected to be frequently present in the kidneys of rats killed at about four months. These in fact were not found.

(3) The constant finding of excess red blood cells and casts in the urine of rats after four weeks in experiment 2 was not associated with any histological evidence of pyelonephritis when the rats were killed between six and nine weeks; the kidneys of two of these rats had no obvious histological abnormalities.

(4) The intensity of the renal damage appeared to be related to the dose of cadmium received. The lesions were more marked in the rats of experiment 2 which had received a total dose in 45 weeks of almost double the amount received by those in experiment 3 in 52 weeks.

(5) The appearance of early lesions after four months coincided with the attainment of a maximum cadmium concentration in the kidneys.

(6) No organisms were grown when cultures were

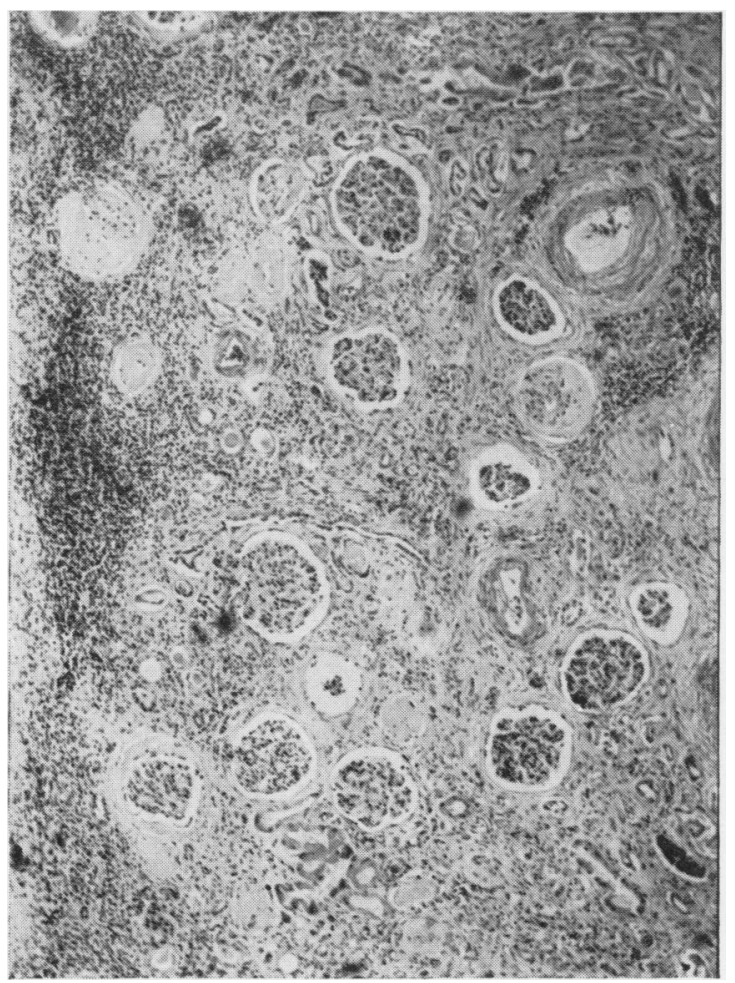

FIG. 11.-Male, aged 54 years. Haematoxylin and eosin, $\times 62$. Cortex showing gross tubular atrophy, ischaemic and degenerative glomerular lesions, interstitial fibrosis, and marked subcapsular lymphocytic infiltration. made at 12 months from the kidneys of two control rats and three cadmium-injected rats with grade 3 histological lesions (one with polymorphonuclear leucocyte tubular casts). Two colonies of $E$. coli were, however, grown from the kidney of one cadmium-injected rat, which had grade 2 histological lesions and was killed at 12 months.

(7) The most advanced lesions were similar to those found in the kidneys of one man who died in uraemia, the result of chronic cadmium poisoning (Case AI, Bonnell, 1955). In his kidneys there was the same marked tubular atrophy but in addition there was pronounced subcapsular infiltration with chronic inflammatory cells and many glomeruli were transformed into fibrohyaline discs (Fig. 11).

It is of interest that the tubular lesions in rats which were killed at 12 months, but which had not received injections after five and six months, were of comparable severity to those found in rats which had been injected with cadmium up to 12 months. The progression of the renal lesion after dosage had been stopped is of particular interest. It has been shown that in men the onset of cadmium proteinuria can occur many years after the last exposure to cadmium (Bonnell et al., 1959). This suggests that a progressive toxic process may be present, eventually interfering with renal function, the first sign of which may not appear until many years after cessation of exposure. As with the rats in these experiments, the role of cadmium in relation to the progressive nature of the lesions is not clear. In the experimental animals there was a release of cadmium from the liver and this may have contributed to the production of the renal lesions, in addition to any damage caused by the cadmium already present in the kidneys.

The tissue concentrations of cadmium in liver and kidneys obtained at necropsy from five men who died of chronic cadmium poisoning are summarized in Table 2, together with years of exposure

TABLE 2

CADMIUM CONCENTRATION ( $\mu$ g./g.) OF LIVER AND KIDNEY FROM HUMAN CASES OF CHRONIC CADMIUM POISONING

\begin{tabular}{|c|c|c|c|c|c|}
\hline Case No. & $\begin{array}{c}\text { Years } \\
\text { between } \\
\text { Last } \\
\text { Exposure } \\
\text { and Death }\end{array}$ & $\begin{array}{c}\text { Protein- } \\
\text { uria }\end{array}$ & $\begin{array}{c}\text { Renal } \\
\text { Damage }\end{array}$ & $\begin{array}{l}\text { Kidney } \\
\text { (Cortex) }\end{array}$ & Liver \\
\hline $\begin{array}{c}\text { A1 } \\
\text { (Bonnell, 1955) }\end{array}$ & 2 & + & + & 62 & 330 \\
\hline $\begin{array}{l}\text { B2 } \\
\text { (Bonnell, 1955) } \\
\text { (Smith et al., } \\
\text { 1957) }\end{array}$ & 5 & + & - & 150 & 160 \\
\hline $\begin{array}{l}\text { B6 } \\
\text { (Bonnell, 1955) }\end{array}$ & 5 & - & 一 & 360 & 300 \\
\hline $\begin{array}{l}\text { Unpubblished } \\
\text { data (Bonnell) }\end{array}$ & 10 & - & - & 170 & 65 \\
\hline $\begin{array}{c}\text { B1 } \\
\text { (Bonnell, 1955) }\end{array}$ & 20 & + & - & 395 & 145 \\
\hline
\end{tabular}


and the interval between last exposure and death. Other cases reported by Lane and Campbell (1954) and Friberg (1950a) are not in accordance with the above data. The concentrations of cadmium reported by them were of a different order of magnitude.

Stitch (1957) estimated spectrographically the cadmium content of tissues obtained at necropsies of people who died as the result of accidents and in whom there had been no occupational exposure to cadmium. The kidneys were found to contain the highest concentration of cadmium, suggesting that they selectively retain cadmium. It is possible that the concentration of cadmium in the kidneys following occupational exposure of men or experimental dosage of animals continues to increase until there is sufficient cadmium present in the renal parenchyma to cause damage. Certainly the concentration of cadmium in the kidneys remains at a high level both in men and in experimental animals (Figs. 7 and 9 and Table 2). This maintenance of renal cadmium levels is unlike the rapid fall of liver cadmium concentrations upon cessation of exposure, again demonstrable in both men and experimental animals.

We should like to thank Dr. Donald Hunter, Director of the Department for Research in Industrial Medicine, for his encouragement, and Professor Dorothy Russell for advice and for examining the kidneys of the animals in experiment 2 , and also for permission to reproduce the photomicrograph of Fig. 11. We are indebted to Mr. B. T. Biles who carried out all the histological preparation and $\mathrm{Mr}$. K. Baker who prepared and analysed the animal tissues for cadmium. We should also like to thank Mr. J. King for the photomicrographs and Dr. J. C. Smith for making available the tissue analyses of cases B1 and B6 in Table 2.

\section{REFERENCES}

Alsberg, C. L., and Schwartze, E. W. (1919). J. Pharmacol., 13, 504. Bonnell, J. A. (1955). Brit. J. industr. Med., 12, 181.

- Kazantzis, G., and King, E. (1959). Ibid., 16, 135.

Dalhamn, T., and Friberg, L. (1957). Acta path. microbiol. scand.,

Fourman, P., McCance, R. A., and Parker, R. A. (1956). Brit. J. exp. Path., 37, 40

Friberg, L. (1948). J. industr. Hyg., 30, 32.

(1950a). Acta med. scand., Suppl. 240.

(1950b). Arch. industr. Hyg., 1, 458.

(1952). A.M.A. Arch. industr. Hyg. ., 30.

Johns, C. O., Finks, A. J., and Alsberg, C. L. (1923). J. Pharmacol., 21, 59 .

Lane, R. E., and Campbell, A. C. P. (1954). Brit. J. industr. Med., $11,118$.

Marmé, W. (1867), $Z$. rationelle Med., 29, 125.

Milne, M. D., Muehrcke, R. C., and Heard, B. E. (1957). Brit. med. Bull., 13, 15.

Princi, F., and Geever, E. F. (1950). Arch. industr. Hyg., 1, 651.

Prodan, L. (1932). J. industr. Hyg., 14, 174.

Relman, A. S., and Schwartz, W. B.,(1958). Amer. J. Med., 24, 764. Schwarz, L., and Otto, A. (1925). Z. Hyg. Infekt.-Kr., 104, 364. Saxton, J. A., and Kimball, G. C. (1941). Arch. Path. (Chicago), 32, 951 .

Severi, A. (1896). Arch. Sci. med., 20, 293.

Smith, J. C., Kench, J. E., and Smith, J. P. (1957). Brit. J. industr. Med., 14, 246.

Stitch, S. R. (1957). Biochem. J., 67, 97.

Wilson, R. H., DeEds, F., and Cox, A. J. (1941). J. Pharmacol., 71, 222 . 